\title{
ARQUITETURA DA INFORMAÇÃO EM WEB SITE DE PERIÓDICO CIENTÍFICO
}

\section{Maria Fernanda Sarmento e Souza \\ Miriam Celí Pimentel Porto Foresti \\ Silvana Aparecida Borsetti Gregorio Vidotti}

\begin{abstract}
Resumo
Investigam-se elementos da Arquitetura da Informação à serem considerados em web site de periódico científico, descrevendo-se critérios de qualidade e variáveis que devem ser mantidos, a fim de garantir a permanência das funções memória e disseminação, inerentes ao processo de comunicação científica. Apresentam-se o 'Modelo para análise de estrutura de periódicos científicos eletrônicos' e um estudo descritivo e comparativo dos web site das revistas Ciência da Informação On-line e DataGramaZero. Resultados apontam a Arquitetura da Informação como uma área de estudos que poderá subsidiar bibliotecários, autores e leitores na identificação de periódicos de qualidade, e editores no desenvolvimento de projetos de periódicos científicos eletrônicos.
\end{abstract}

\section{Palavras-chave}

Comunicação Científica; Ciência da Informação; Arquitetura de Informação; Periódico Científico Eletrônico; Internet; web site

\section{INFORMATION ARCHITECTURE IN A SCIENTIFIC JOURNAL WEB SITE}

\begin{abstract}
Information Architecture elements were investigated for consideration in a scientific journal web site, describing the quality criteria and variables which must be maintained to ensure the permanence of archival and dissemination functions, inherent in the scientific communication process. The 'Model for analysis of the structure of electronic scientific journals' with a descriptive and comparative study of Ciência da Informação On-line and DataGramaZero web sites were presented. Results show Information Architecture as an area of study that may help librarians, authors, and readers identify quality periodicals, and editors develop scientific electronic journals.
\end{abstract}

\section{Keywords}

Scientific Communication; Information Science; Information Architecture; Electronic Scientific Journal; Internet; web site 


\section{INTRODUÇÃO}

As novas tecnologias da informação trouxeram um novo desafio para a área da Comunicação Científica, envolvendo a mudança de hábitos e práticas em processos de produção e disseminação do conhecimento em meios digitais. Os sistemas hipertextuais vêm sendo utilizados com freqüência crescente no meio acadêmico e científico, em particular nos periódicos científicos eletrônicos, possibilitando ao usuário acessar de forma rápida as informações contidas na sua estrutura. No entanto, esses sistemas precisam ser desenvolvidos de modo a auxiliar o usuário durante a busca e o acesso à informação no site. Essas questões têm merecido atenção especial na Ciência da Informação, tendo como foco de estudo o armazenamento, acesso e a disseminação de informações.

Considerando a necessidade de assegurar a qualidade do periódico científico na sua transição para o suporte eletrônico e a preocupação de identificar novos critérios que atendam às especificidades desta mídia, analisou-se a evolução ocorrida nas publicações nesse período de transição e realizou-se um estudo descritivo sobre os aspectos que devem ser considerados no momento da produção de periódico científico eletrônico e/ou transferência de material publicado em revistas impressas para aquele meio, visando à manutenção das funções básicas das publicações periódicas e considerando os elementos da Arquitetura da Informação de web site (SARMENTO E SOUZA, 2002).

O presente trabalho focaliza os resultados obtidos naquela investigação, em relação à descrição e análise comparativa dos web site de dois periódicos científicos eletrônicos nacionais da área de Ciência da Informação, Ciência da Informação On-line e Datagramazero - Revista de Ciência da Informação, tendo como referencial os estudos sobre Arquitetura da Informação desenvolvidos por Rosenfeld e Morville (1998) e Straioto (2002) e aplicando-se parte do 'Modelo para análise de estrutura de periódicos científicos eletrônicos’ (Anexo A).

\section{ARQUITETURA DA INFORMAÇÃO: DEFINIÇÃO E APRESENTAÇÃO DOS ELEMENTOS BÁSICOS}

Segundo Rosenfeld e Morville (1998), a Arquitetura da Informação envolve quatro elementos básicos: sistemas de organização: maneiras como o conteúdo do site pode ser agrupado; sistemas de rotulagem: forma como é denominado o conteúdo do grupo informacional; sistemas de navegação: barras de navegação e mapas do site que permitem ao usuário mover-se entre as partes do conteúdo ou navegar fora dele; sistemas de busca: 
auxiliam o usuário a formular consultas que podem resultar em documentos relevantes.

Os autores salientam que os quatro elementos da arquitetura já mencionados devem ser observados durante o desenvolvimento de web sites, ou seja, um conjunto de páginas interligadas que formam um sistema informacional. Neste estudo, considera-se que as páginas do periódico científico eletrônico compõem um web site ou, de forma simplificada, um site.

Straioto (2002) apresentou um estudo sobre os quatro elementos da Arquitetura da Informação propostos por Rosenfeld e Morville (1998), utilizando-os para a análise de portais acadêmico-científicos. Incluiu, em seu estudo, elementos adicionais como conteúdo das informações (RODRIGUES, 1998); usabilidade do site (NIELSEN, 1998; GAFFNEY, 2001) e alguns tipos de documentos (CLEVELAND, 1999).

SISTEMAS DE ORGANIZAÇÃO

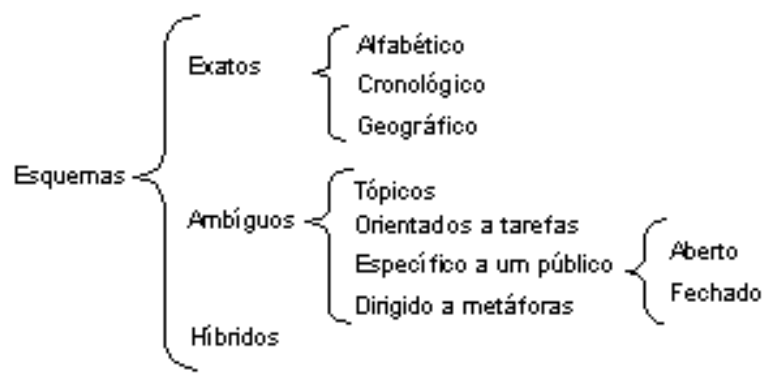

Estruturas $\left\{\begin{array}{l}\text { Hierárquica (Top-down) - geral } \rightarrow \text { específico } \\ \text { Hipertexto } \\ \text { Base relacional (Bottom-up) - específico } \rightarrow \text { geral }\end{array}\right.$
SISTEMAS DE NAVEGAÇÃo

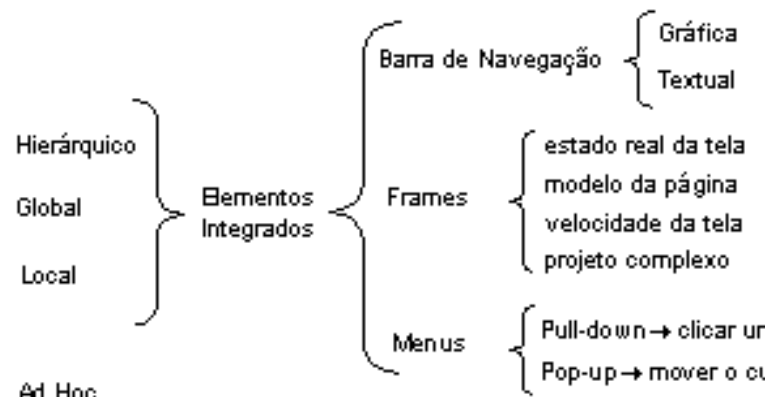

Ad Hoc

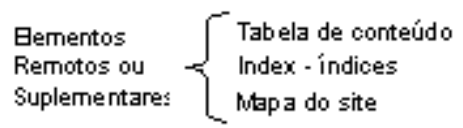

\section{SISTEMAS DE BUSCA}

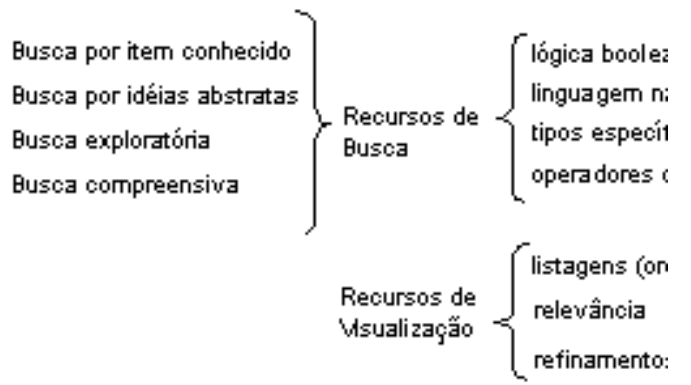




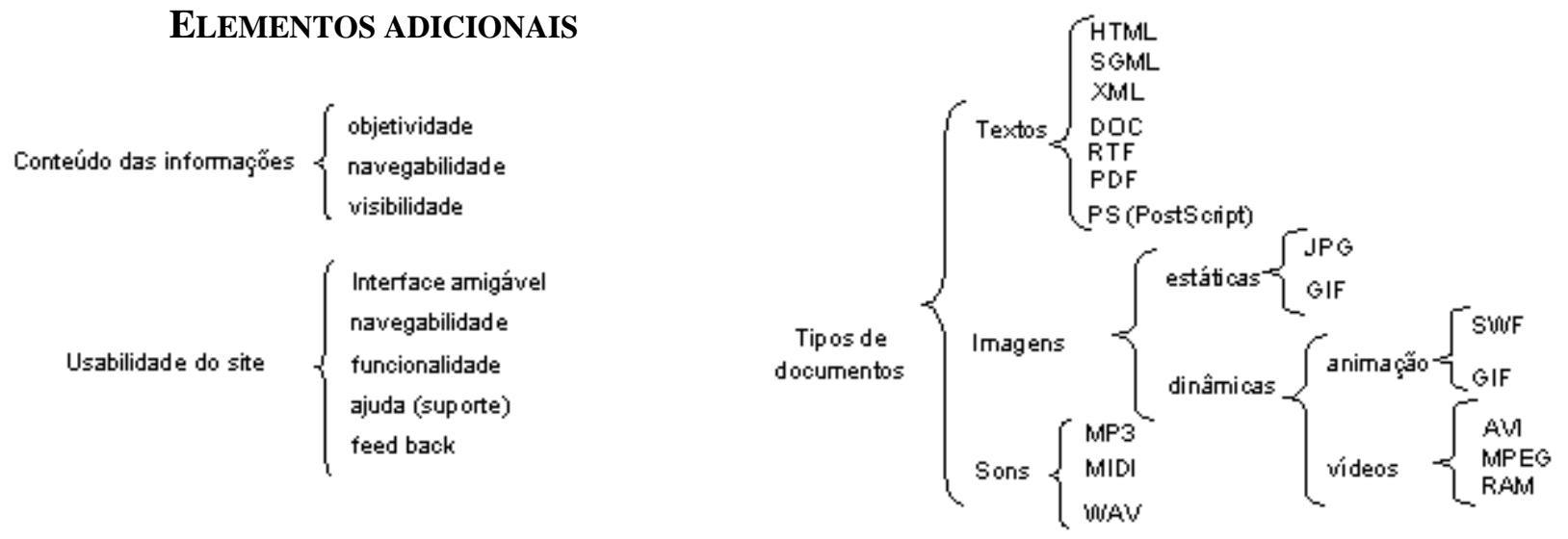

Figura 1. Elementos da Arquitetura da Informação (STRAIOTO, 2002).

Para atender aos objetivos do presente trabalho, na análise de sites de periódicos científicos foram considerados alguns elementos técnicos apontados por Rosenfeld e Morville (1998) reunidos e complementados por Straioto (2002). Com o intuito de facilitar a melhor compreensão da Arquitetura da Informação, apresentam-se, a seguir, explicações resumidas desses elementos:

Sistemas de organização: A organização da informação em web sites é o principal fator para a determinação do sucesso dos mesmos. Podem existir múltiplos sistemas de organização para um mesmo conteúdo informacional. Os ‘sistemas de organização' estão divididos em ‘esquemas de organização’ e ‘estruturas de organização’ (RosenfELD; MoRVILLE, 1998, p.26).

\section{$\checkmark$ Esquemas de organização:}

- Exatos: separam as informações em seções exclusivas e bem definidas. Possuem um esquema amigável de navegação, são fáceis de projetar e manter. Porém, faz-se necessário que o usuário saiba a informação específica/exata que procura. Entre as divisões destes esquemas, interessam ao presente trabalho o exato alfabético e o exato cronológico.

- Ambíguos: dividem a informação em categorias definidas por características determinadas pelos desenvolvedores de sistemas. São difíceis de se projetar e manter. No entanto, são muito úteis porque auxiliam os usuários que não sabem exatamente o que procuram, e muitas vezes, não sabem o nome correto do rótulo ou têm apenas uma vaga informação a respeito do 
assunto. Destaca-se o esquema ambíguo específico a um público, utilizado por um público claramente definido, que possui os mesmos objetivos específicos e determinados. O esquema é aberto quando usuários de outros conteúdos têm acesso a esse site ou seções do mesmo. Neste caso, as seções ou artigos do periódico.

$\checkmark$ Estruturas de organização: são importantes no desenvolvimento dos sites, pois definem os caminhos que podem ser seguidos pelos usuários. As principais estruturas de organização que se aplicam em arquitetura de sites e Intranet são:

- Hierárquica (top-down): a base de uma boa Arquitetura da Informação é o desenho da hierarquia. Pode-se iniciar identificando a área de conteúdo mais abrangente, a partir da qual serão distribuídos os conteúdos secundários ou subitens para acesso ao conteúdo. Deve-se definir na construção da estrutura hierárquica a sua abrangência (breadth - número de opções de cada nível da hierarquia) e sua especificidade (depth - número de níveis na hierarquia). Em consideração à quantidade de opções em cada nível da hierarquia - abrangência, Rosenfeld e Morville (1998, p.38) salientam que a estrutura deve ser planejada respeitando-se os limites cognitivos da mente humana, de acordo com a regra de sete mais ou menos dois (MILLER, 1956). Em relação ao número de níveis na hierarquia - especificidade, deve-se considerar um máximo de quatro a cinco níveis para o usuário acessar a informação. O desenvolvimento de sites que não cumprem essas regras básicas pode prejudicar a busca de informação pelo usuário.

hipertexto possui dois tipos de componentes: itens ou partes de informações que interligados formam sistemas hipermídia. Essas ligações podem ocorrer entre texto, vídeos, sons e imagens mantendo ou não uma hierarquia, e gerando um sistema organizacional em forma de rede informacional;

- Base relacional (bottom-up): utiliza informações organizadas em bases de dados relacionais que permitem a busca por informações específicas que podem ser realizadas em qualquer campo de registro. É considerada uma estrutura de organização bottom-up por partir de uma informação específica e chegar a um assunto geral.

Sistemas de navegação: Enquanto um bom desenho da estrutura hierárquica organizacional pode reduzir a possibilidade do usuário se sentir perdido no site, um sistema de navegação complementar é muitas vezes necessário, no sentido de fornecer maior visualização do 
contexto e permitir maior flexibilidade de movimentação dentro do mesmo. No entanto, há um constante desafio no desenho do sistema de navegação, pois é necessário manter o equilíbrio entre a movimentação e o oferecimento de opções de link para o usuário. O bom desenho do sistema de navegação é fator crítico na determinação da qualidade do site. $\mathrm{O}$ sistema de navegação é composto por uma variedade de elementos, entre os quais destacamse:

$\checkmark$ Hierárquico: a página principal do site possui ramificação geral da estrutura, apresentando opções secundárias que serão subdivididas.

$\checkmark$ Global: complementa o sistema hierárquico de navegação, por meio de barras de navegação, menus ou links presentes em todas as páginas do site, possibilitando maior movimentação vertical (profundidade) e lateral (largura) dentro do mesmo.

$\checkmark$ Local: específico do conteúdo apresentado, permanecendo presente na tela somente enquanto determinado assunto está sendo abordado. Complementa a navegação global.

$\checkmark$ Ad Hoc: links inseridos no corpo do texto, que podem ser palavras ou frases, fornecendo informações adicionais sobre um assunto.

$\checkmark$ Elementos auxiliares da navegação: os mais comuns são aqueles integrados ao próprio conteúdo das páginas do site. Destacam-se:

- Barras de navegação: coleção de links de hipertexto agrupados em uma página, podendo estar na forma gráfica como uma imagem mapeada ou como imagens dentro de uma estrutura de tabela ou mesmo baseada em texto;

- Frames: sub-janelas nas quais são apresentadas informações independentes entre si. São utilizados como forma de aplicação de barras de navegação textuais ou gráficas, separando o sistema de navegação do conteúdo do site. A utilização dos frames deve ser planejada de acordo com o espaço que ocuparão na tela. 
Sistemas de rotulagem: Rótulo é uma forma de representar um conjunto de informações utilizando uma palavra ou um ícone, de modo a facilitar a recuperação da informação e a navegação do usuário dentro do site. Os formatos de representação são: textual ou iconográfico. Esses rótulos são utilizados dentro dos sistemas de navegação, muitas vezes como termos de indexação para classificar o conteúdo do site. Também podem ser aplicados na definição de cabeçalhos.

Sistemas de busca: Este elemento é empregado na Rede Internet para permitir a localização de informações que podem estar armazenadas em qualquer computador conectado à ela. É interessante que seja empregado um sistema de busca interno em web sites que possuem grande volume de informações, facilitando a localização das mesmas pelo usuário. No entanto, Rosenfeld e Morville (1998) lembram que as ferramentas de busca não conseguem mapear e indexar todas as informações apresentadas na Rede pelo fato de ocorrer um grande número de inclusões e exclusões de sites na Internet diariamente. As formas de busca utilizadas podem demonstrar a variedade de expectativas dos usuários, e estão assim divididas: por item conhecido, por idéias abstratas, exploratória e compreensiva. Os recursos para efetuar a busca podem ser: lógica booleana, linguagem natural, tipos específicos de itens e operadores de proximidade. Os recursos para a apresentação dos documentos recuperados podem ser listagens (ordenadas), relevância e refinamentos de busca.

Straioto (2002) aponta outros elementos citados na literatura por Rodrigues (1998), Nielsen (1998), Gaffney (2001) e Cleveland (1999) que devem ser considerados na construção de sites acadêmico-científicos para Internet, considerando a interação do usuário ou público-alvo e sua forma subjetiva de utilização do sistema. Conteúdo informacional e usabilidade são elementos relacionados com a qualidade da Arquitetura da Informação do site, proporcionando ao usuário informações objetivas e claras, enquanto o item tipos de documentos diz respeito à estruturação e apresentação das informações, podendo também ser considerado um elemento da Arquitetura da Informação:

Conteúdo das informações: deve-se levar em conta a objetividade, a navegabilidade e a visibilidade. A objetividade implica utilizar uma linguagem que auxilie no acesso rápido e eficiente à informação; a navegabilidade é responsável por fazer o usuário recuperar 
rapidamente a mesma; a visibilidade é a organização visual das informações no site, observando-se o uso adequado de recursos tecnológicos.

Usabilidade do site: é a capacidade de um sistema (programa ou web site) ser utilizado de maneira eficiente e ser aceito pelo usuário. Para isto, deve possuir cinco características básicas e fundamentais: ser de fácil apreensão, eficiente na forma de uso, fácil de ser lembrado/memorizado, apresentar poucos erros e apresentar visual agradável. Os itens principais da usabilidade são: interface amigável; navegabilidade; funcionalidade; suporte de ajuda e feedback.

Tipos de documentos: Formatos apontados por Cleveland (1999): Tagged Image File Format (TIFF), Graphics Interchange Format (GIF), Joint Photographics Expert Group (JPEG), American Standard Code for Information Interchange (ASCII), Unicode Standard (UNICODE), Rich Text Format (RTF), DOC, Adobe PostScript (PS), Portable Document Format (PDF), Standard Generalized Markup Language (SGML), Hypertext Markup Language (HTML) e Extensible Markup Language (XML). Além desses foram acrescentados formatos de som e imagens estáticas e dinâmicas, considerando-se para estas últimas imagens animadas e audiovisuais, são eles:

- Formatos de som: Moving Picture Experts Group, Audio Layer 3 (MP3), Musical Instruments Digital Interface (MIDI) e Wave (WAV).

- Formatos de vídeos: Audio Video Interleaved (AVI), Motion Pictures Experts Group (MPEG), Real Media (RM ou RAM).

- Formatos de imagens dinâmicas: além dos GIFs animados, temos os ShockWave Flash (SWF).

Em seu estudo, Cleveland (1999) salientou que os formatos dos documentos possuem características que precisam ser observadas, tais como: legibilidade por máquina/computador, exibição de caracteres multilíngües, preservação de layout, possibilidade de ser editado, tamanho de arquivo, páginas múltiplas, ser estruturado ou nãoestruturado, apresentação multimídia, suportar vínculos, exibição em tela, impressão, 
disponibilidade para os mecanismos de busca, grau de uso e custos com a manutenção do recurso. É preciso observar aqueles que melhor atendam às exigências do projeto de publicação eletrônica e ao propósito da aplicação na Internet.

\section{DESCRIÇão E ANÁLISE dOS RESULTADOS}

Com base nos elementos da Arquitetura da Informação apontados por Rosenfeld e Morville (1998) e Straioto (2002) foi elaborado o 'Modelo para análise de estrutura de periódicos científicos eletrônicos’ (SARMENTO E SOUZA, 2002), aplicado na análise de dois periódicos científicos eletrônicos nacionais da área da Ciência da Informação que apresentam os trabalhos na íntegra, gratuitamente na Internet. O primeiro, Ciência da Informação On-line (CIOnline - http://www.ibict.br), possui versão impressa e eletrônica; o segundo, DataGramaZero - Revista de Ciência da Informação (http://www.dgz.org.brT ou http://www.dgzero.org.br), apresenta apenas a versão eletrônica. Foram analisados todos os fascículos de cada revista, disponíveis na Internet até dezembro de 2001.

A tabela 1 sintetiza os elementos comuns e divergentes da Arquitetura da Informação dos web site das revistas investigadas. 
Tabela 1. Comparação das estruturas dos periódicos CIOnline e DataGramaZero, com relação a Arquitetura da Informação.

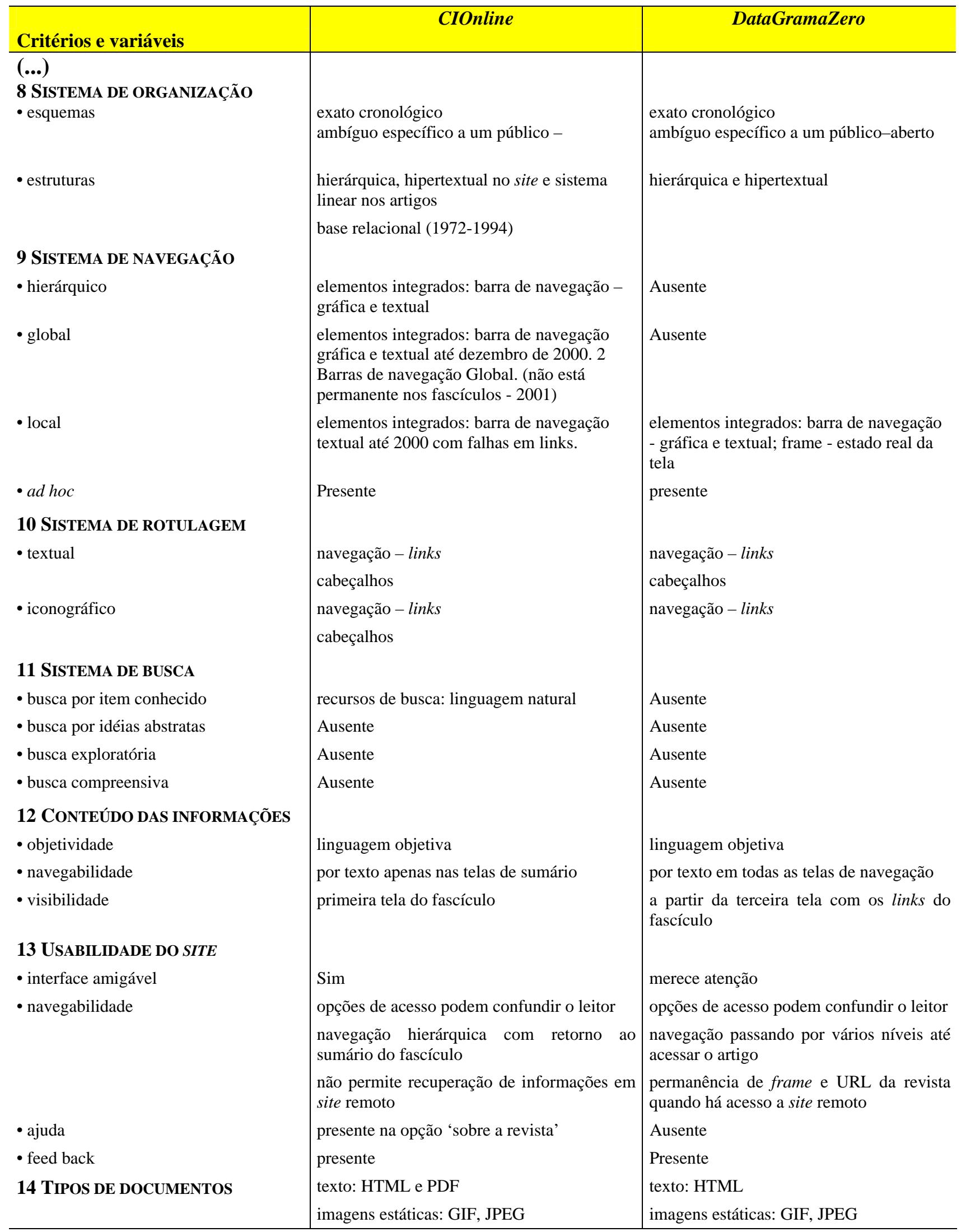


Pelos dados resumidos na tabela 1, algumas considerações podem ser feitas com relação aos critérios e variáveis indicados nos itens 8 a 13 do 'Modelo para análise de estrutura de periódicos científicos eletrônicos’.

Assim, pode-se afirmar que a revista CIOnline tem uma estrutura simples com relação à Arquitetura da Informação, apresentando na tela inicial dos fascículos, link para resumo dos trabalhos, e nas telas de resumos link para email de autor e arquivo PDF. Não permite ao usuário ter acesso aos endereços de links presentes no corpo do texto ou no referencial dos artigos científicos.

O menu que aparece à direita na tela inicial dos fascículos não fica permanente durante a navegação e deixa de aparecer a partir de 2001. Nesse menu encontram-se os rótulos que fornecem informações sobre o IBICT e, ao serem acionados, apresentam a mensagem ‘Página não encontrada', indicando falha na construção do sistema.

Entre os rótulos presentes, um deles - Autores - pode confundir o usuário, levando-o a acessar "Informações aos autores” e não ao nome dos autores.

Até o ano de 2000, o sistema apresenta dois sistemas de navegação Global, desaparecendo um deles a partir de 2001. A ausência do sistema de navegação local dificultou bastante o acesso às informações, principalmente porque o site não apresenta sistema de busca para o período estudado.

Pelo fato da CiOnline atualmente estar no site do IBICT, por apresentar seus artigos em formato PDF e as páginas de resumos não apresentarem seu URL e indexação da mesma, não é possível a um usuário acessar a revista e os artigos. As seções do periódico, portanto, não atendem às características de um sistema aberto, salientado por Rosenfeld e Morville (1998).

Ambas as revistas utilizam esquema exato cronológico, quando apresentam uma página com os fascículos publicados.

Quanto à revista DataGramaZero, apesar de ter algumas falhas de links, questão comum de ocorrer em publicações em suporte eletrônico, permite ao usuário recuperar as informações ali apresentadas.

O periódico DataGramaZero, por ser exclusivamente eletrônico, tem uma apresentação diferente da CIOnline. Não possui um sumário do fascículo, o que facilitaria a visualização do todo pelo leitor. Inicialmente tem um sistema de navegação linear e a partir da quarta página de navegação inclui links que permitem o acesso às informações sobre a temática do fascículo em sites remotos. Contudo, o sistema de navegação local do periódico é 
mantido na página, exceto quando são acessados os endereços da ANCIB, UNB, UFRJ e IBICT, instituições ligadas direta ou indiretamente (por intermédio do Conselho Editorial) à produção do periódico. Por um lado, este procedimento é aparentemente válido para um web site de periódico científico, por fazer o leitor permanecer no site para concluir a leitura do artigo científico. Por outro lado, percebe-se que a manutenção do frame às vezes dificulta a leitura no monitor. Em alguns casos a seqüência de links no site remoto levou a um total de cinco frames na tela, fazendo com que a área de visualização da informação ficasse totalmente prejudicada, não havendo a alternativa para sair do site da revista.

O sistema de navegação utiliza rótulos com linguagem objetiva, porém, o rótulo 'Autores' apresenta o nome dos autores que publicaram artigos originais no respectivo fascículo, desconsiderando os autores das demais Seções.

A partir da análise dos periódicos foi desenvolvido o sistema de navegação de cada um deles, apresentados a seguir.

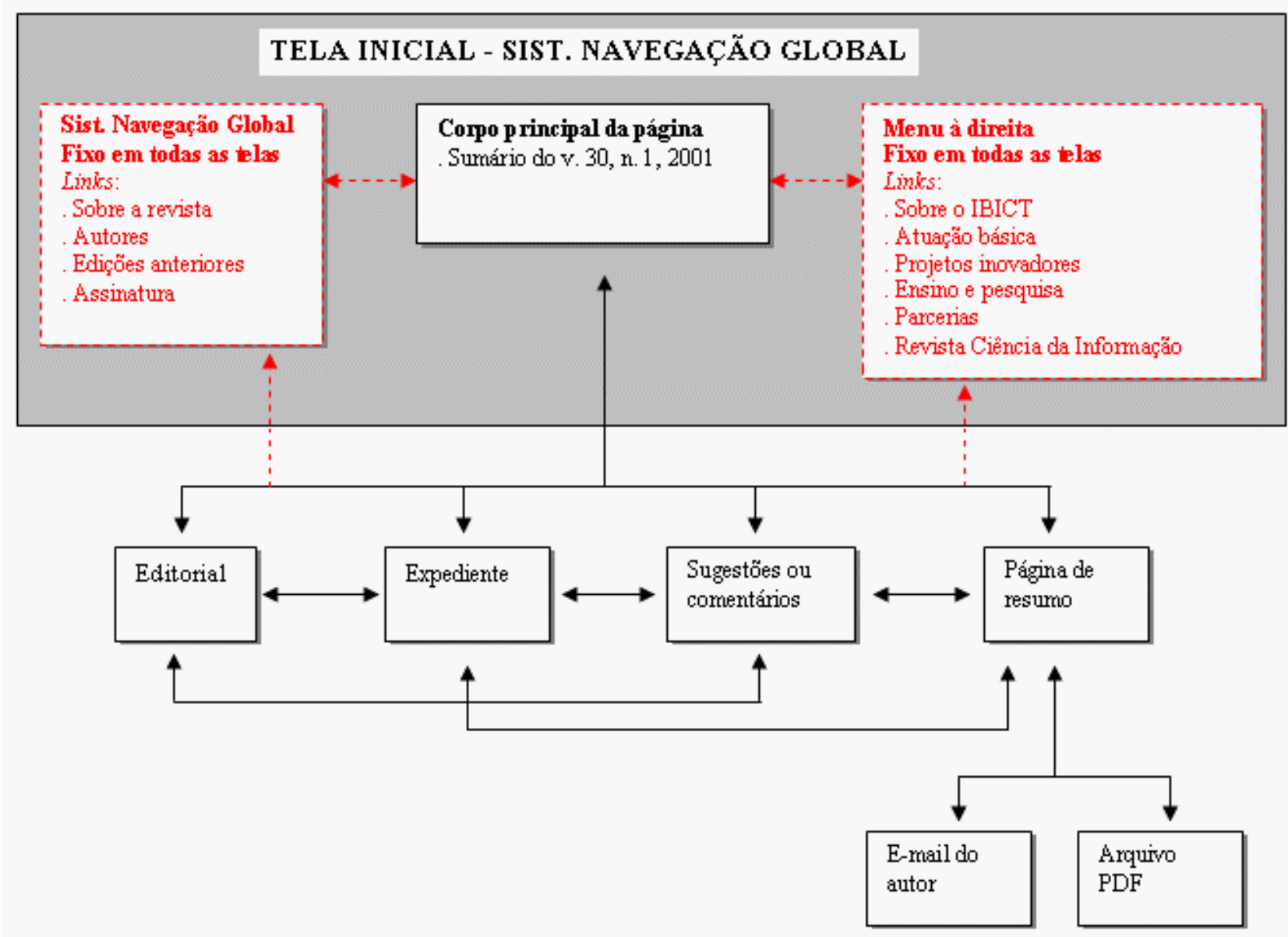

Figura 2. Representação do sistema de navegação da CIOnline. (SARMENTO E SoUZA, 2002). 
Em preto é representado o sistema de navegação vigente no web site da CIOnline. Em vermelho o 'sistema de navegação global' e menu 'à direita', que faziam parte da estrutura do mesmo até o v.29 e telas intermediárias de navegação do v.30, n.1, 2001. Este sistema caracteriza uma hierarquia larga e superficial do site.

Com relação ao período estudado (1995 a 2001), percebe-se na hierarquia da revista que o usuário passa por três telas de navegação até acessar o artigo científico em formato PDF. Se, por um lado, há rapidez no acesso à informação dentro do fascículo, por outro percebe-se pouca interatividade do leitor com o texto em PDF, o qual não apresenta links com sites remotos. No período analisado, todos os arquivos PDF possuíam construção linear, sendo permitida impressão e gravação dos mesmos. A ausência de hipertexto nesses arquivos inviabiliza a busca e o acesso às informações contidas em links, incluindo recuperação imediata de referências eletrônicas citadas no artigo, e que as vezes eram referências de artigos publicados na própria revista. Portanto, as vantagens de acesso rápido a textos eletrônicos, apontadas por Cleveland (1999) não foram observadas na CIOnline. 


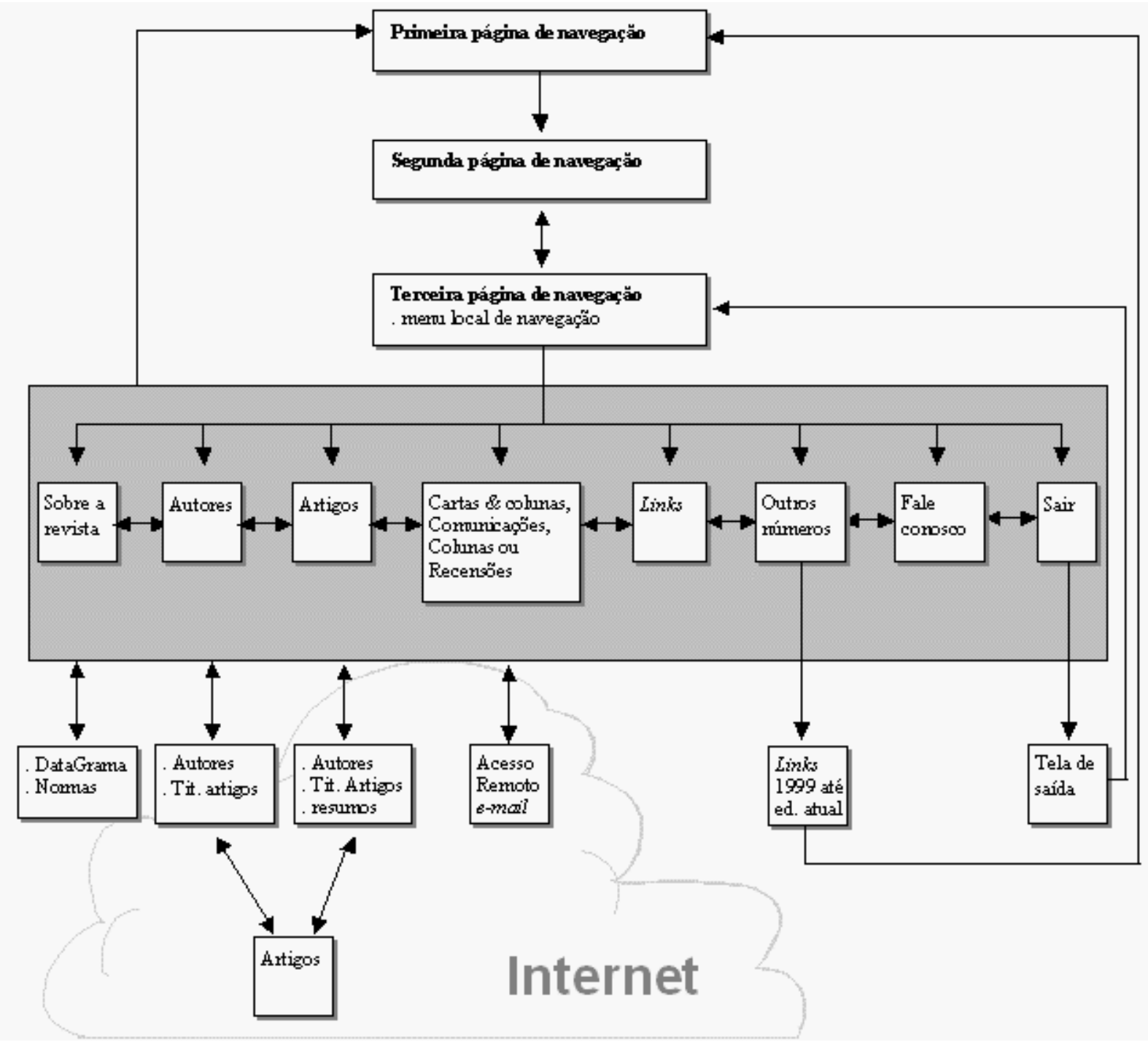

Figura 3. Representação do sistema de navegação da DataGramaZero. (SARMENTO E SouZA, 2002).

O quadro cinza representa o sistema de navegação local que pode permanecer fixo quando ocorre o acesso a outros endereços eletrônicos na Internet. Este sistema caracteriza uma hierarquia estreita e profunda no site.

Quanto à usabilidade do site, destaca-se que o acesso a determinado artigo científico pode levar o usuário a passar por até nove telas de navegação, o que pode tornar bastante cansativo, tendo em vista que o site não apresenta nenhum sistema de busca. É importante lembrar que, segundo Rosenfeld e Morville (1998) o limite razoável seria de cinco níveis de informação.

No período analisado (1999 a 2001), os arquivos de texto disponíveis são no formato HTML e apresentam uma construção hipertextual, confirmando as vantagens apontadas por 
Cleveland (1999). São incluídos links com endereço eletrônico dos autores; com outros artigos do mesmo autor presentes na DataGramaZero; links de referências citadas com o artigo completo; interatividade com outros endereços eletrônicos relativos ao assunto. Os arquivos de imagem encontrados foram em GIF e JPG, também apontados por Cleveland (1999).

O emprego correto desses elementos facilita a movimentação do usuário durante a navegação e a localização das informações, permitindo um acesso mais fácil e rápido.

\section{CONSIDERAÇÕES FINAIS}

O estudo desenvolvido permite concluir pela pertinência da aplicação dos elementos de Arquitetura da Informação na estrutura das páginas de periódicos científicos eletrônicos distribuídos na Internet. A estruturação adequada dos sistemas de navegação, busca, rotulagem, organização, conteúdo informacional, tipos de documentos e usabilidade do site permitem que o leitor/usuário encontre rapidamente as informações desejadas. Esses elementos da Arquitetura da Informação de web site tornam-se importantes uma vez que o leitor/usuário busca na mídia eletrônica maior rapidez no acesso aos artigos.

No que se refere ao estudo das duas revistas, em particular, as análises realizadas indicam algumas vantagens da revista Ci On-Line em relação ao acesso à informação e da DatagramaZero, em relação à navegação e ao acesso a sites remotos, embora ambas necessitem implementar novos elementos da Arquitetura da Informação que possam contribuir para a melhoria da qualidade dos seus sites. Ressalta-se, aqui, a ausência de sistemas de buscas nessas revistas, elemento fundamental da transição da mídia impressa para a eletrônica, agilizando e ampliando o acesso à informação científica.

Resultados obtidos confirmam a pertinência da Arquitetura da Informação como um campo de estudo promissor a subsidiar profissionais bibliotecários, autores e usuários de revistas científicas, na identificação de periódicos eletrônicos de qualidade e editores de revistas em linha, no desenvolvimento de seus projetos. 


\section{REFERÊNCIAS}

Cleveland, G. Selecting Electronic Document Formats. National Library of Canada, July, 1999. Disponível em: <http://www.ifla.org/VI/5/op/udtop11/udtop11.htm>. Acesso em: 19 abr. 2001.

GAFFNEY, G. Usability: does it matter ? Disponível em:

<http://www.infodesign.com.au/articles/default.html>. Acesso em: 7 set. 2001.

MiLleR, G. The magical number seven, plus or minus two: some limits on our capacity for processing information. Psychological Review, 63, 2, p.81-97, 1956.

NIELSEN, J. What is “usability”? Zdzet Developer, set. 1998. Disponível em: <http://www.zdnet.com/devhead/stories/articles/0,4413,2137671,00.html>. Acesso em: 29 ago. 2001.

RODRIGUES, B. Os três mandamentos: objetividade, navegabilidade, visibilidade. Webworld, jun. 1998. Disponível em: <http://www.uol.com.br/webworld/tecnologia/webwriting/ write2.htm>. Acesso em: 10 abr. 1999.

Rosenfeld, L.; MoRville, P. Information Architecture for the World Wide Web. Sebastopol, CA: O’Reilly, 1998. 202p.

SARmento e Souza, M. F. Periódicos científicos eletrônicos: apresentação de modelo para análise de estrutura. 2002. 154f. Dissertação (Mestrado em Ciência da Informação) Faculdade de Filosofia e Ciências, Universidade Estadual Paulista, Marília.

StRAIOTO, F. A arquitetura da informação para a World Wide Web: um estudo exploratório. 2002. 120f. Dissertação (Mestrado em Ciência da Informação) - Faculdade de Filosofia e Ciências, Universidade Estadual Paulista, Marília. 
ANEXO A

MODELO PARA ANÁLISE DE ESTRUTURA DE PERIÓDICOS CIENTÍFICOS ELETRÔNICOS

Título

Instituição

Volume(s) $\mathrm{N}^{\mathrm{o}} \mathrm{S}$ Ano Estado Agência Financiadora

1 NORMALIZAÇÃo

\subsection{Periódico no todo}

1.1.1 ISSN e/ou DOI

- existência

- utiliza DOI (referente ao fascículo, referente ao artigo)

- utiliza ISSN da revista impressa

- utiliza ISSN da revista em linha

- inclusão (Tela inicial, demais telas de navegação, arquivos de impressão)

1.1.2 Endereço

- completo (e-mail, URL)

- incompleto

1.1.3 Instruções aos autores

- existência

- completa (incluindo exemplo de referências bibliográficas e links eletrônicos)

- mantém processo de avaliação por pares

- indica normas e exemplos para referências (impressas e eletrônicas)

- indica normas e exemplos para inclusão de links

- indica formatos e tamanho de arquivos eletrônicos (texto e imagens)

- padronização de fonte e softwares

- modo de envio dos trabalhos (correio, e-mail, ftp)

- documentos de aprovação do projeto pelo CEP e/ou CONEP

1.1.4 Armazenamento, distribuição e acesso

- distribuição e meios de acesso: (papel, DVD, CD-ROM, Fita Dat, Internet)

- estrutura de armazenamento e acesso: computador-servidor com espelhamento

\subsection{Fascículo}

1.2.1 Sumário

- existência (língua original)

- existência (bilíngüe)

1.2.2 Legenda bibliográfica

- existência

• inclusão (Tela inicial, demais telas de navegação e arquivos de impressão)

1.2.3 Referências bibliográficas

- normalização (ISO, ABNT, outros)

1.2.4 Errata

• existência com data de inclusão

\subsection{Artigos}

1.3.1 Filiação autor

- indicação completa (fone, fax, e-mail)

- indicação incompleta

1.3.2 Resumo (inclusão sistemática)

- só no idioma do texto

- só em outro idioma que não o do texto

- dois ou mais idiomas

1.3.3 Descritores

- inclusão em todos os artigos

- não inclui

1.3.4 Data e/ou hora (inclusão sistemática)

- do recebimento e/ou aprovação dos artigos

- da inserção dos artigos no meio eletrônico

- da atualização de informações

1.3.5 Paginação

- seqüencial no fascículo 
- sem paginação

1.3.6 Referências e endereços eletrônicos

- existência

- links

1.3.7 Qualidade de apresentação

- de visualização

- de impressão

2 DURAÇão

- tempo ininterrupto de existência

3 Periodicidade

- intervalo regular (indicar quantos fascículos por ano)

- intervalo irregular (atrasada)

- publicação em fluxo contínuo

4 INDEXAÇÃo

- inclusão em bibliografias, abstracts, sumários correntes e impressos ou em CD-ROM

5 DifusÃo

- número de acessos ao fascículo

- número de acessos e/ou download do artigo

- envio por mala direta

- granularidade (artigo, título, número ou volume e parte do documento)

6 COLABORAÇÃo E DIVISÃo DE CONTEÚDO

- existência

7 AUTORIDAdE

- existência de comissão (ou corpo) editorial

8 SISTEMA DE ORGANIZAÇÃo

- esquemas

- estruturas

9 SISTEMA DE NAVEGAÇÃo

- hierárquico

- global

- local

- ad hoc

10 SiSTEMA DE ROTULAGEM

- textual

- iconográfico

11 SISTEMA DE BUSCA

- busca por item conhecido

- busca por idéias abstratas

- busca exploratória

- busca compreensiva

12 CONTEÚDO DAS INFORMAÇÕES

- objetividade

- navegabilidade

- visibilidade

13 USABILIDADE DO SITE

- interface amigável

- navegabilidade

- funcionalidade

- ajuda (suporte)

- feed back

14 TIPOS DE DOCUMENTOS

- textos (HTML, SGML, PDF, outros)

- imagens (estáticas e/ou dinâmicas)

- sons (MP3, MIDI, WAV)

SARMENTO E SOUZA, 2002. 


\section{MARIA FERNANDA SARMENTO E SOUZA}

Mestre em Ciência da Informação e Membro do Grupo de Pesquisa - Novas Tecnologias da Informação, Faculdade de Filosofia e Ciências, UNESP, Marília (SP) Técnica em Informática no Centro de Estudos de Venenos e Animais Peçonhentos (CEVAP), UNESP, Botucatu, (SP)

Rua Dr. Cardoso de Almeida, n. 1431, 18600-005, Botucatu, SP, Brasil e-mail: Hfernanda_sarmento@yahoo.comH ou Hfsarmento@cevap.org.brH

\section{MIRIAM CELÍ PIMENTEL PORTO FORESTI}

Doutora em Educação. Professora do Curso de Pós-Graduação em Ciência da Informação e Membro do Grupo de Pesquisa - Novas

Tecnologias da Informação, Faculdade de Filosofia e Ciências,

UNESP, Marília, SP, Brasil e-mail: Hmfforesti@uol.com.brH

\section{SILVANA APARECIDA BORSETTI GREGORIO VIDOTTI} Doutora em Educação. Professora do Departamento de Ciência da Informação e do Curso de Pós-Graduação em Ciência da Informação e Membro do Grupo de Pesquisa - Novas Tecnologias da Informação, Faculdade de Filosofia e Ciências, UNESP, Marília, SP, Brasil. e-mail: Hvidotti@marilia.unesp.brH ou Hvidotti@flash.tv.brH

Aceito em: 26/06/2004 Aceito em: 26/07/2004 